\title{
A Review of Researches on Teachers' Occupational Burnout in Primary and Middle Schools
}

\author{
Xuechi Yin, Jian Mao, Lan Luo* \\ School of Humanities, Jiangxi University of Traditional Chinese Medicine, Nan Chang, Jiang Xi, China \\ *Corresponding author. Email: 13132814@qq.com
}

\begin{abstract}
In recent years, the problem of job burnout among primary and secondary school teachers in our country has aroused the attention of more and more researchers, and the results of research are increasing. This article briefly introduces the causes and influencing factors of primary and secondary school teachers' job burnout, comprehensively combs the status quo of research in this field from the research focus and research findings, and discusses the main problems and development directions of the research.
\end{abstract}

Keywords: Primary and secondary school teachers, Job burnout, Review, Enlightenment.

\section{INTRODUCTION}

The teaching profession is a profession with more sources of stress and greater stress intensity. Therefore, teachers are prone to job burnout. In recent years, with the deepening of education reforms, the majority of primary and secondary school teachers have felt that the professional pressure is increasing, and the professional burnout of the teacher group has become more and more serious [1]. The focus of this article is to review the research situation of China's primary and secondary school teachers' job burnout.

\section{RESEARCH BACKGROUND}

The research results of domestic teacher burnout were first published publicly in 1990. Therefore, this article screens the documents published in various academic journals and magazines or publicly available dissertations from 1990 to 2021. The theme is "primary and middle school teachers" + job burnout (job exhaustion) "Search CNKI and Wanfang Data Knowledge" to search for resources in CNKI and Wanfang Data Knowledge Service Platform, Weipu Journal Resource Integration Service Platform. A total of nearly a hundred related documents have been obtained. After searching and reading documents, 31 documents that meet the criteria of this article were finally screened out. This article uses the literature search and selection path as shown in Figure 1:

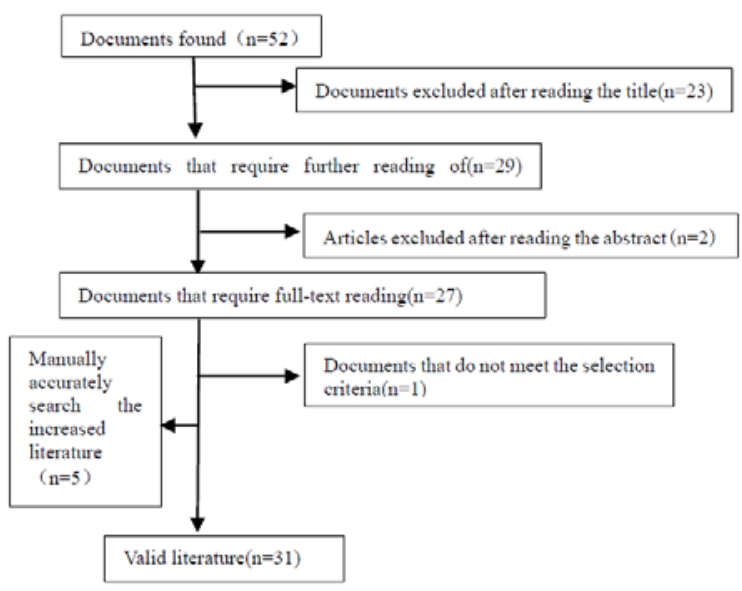

Figure 1 Literature search strategy

\section{THE DEFINITION AND SPECIFIC PERFORMANCE OF THE CONCEPT OF TEACHERS' JOB BURNOUT}

Job burnout was put forward by American psychologist Freudenberger in 1974. It mainly refers to practitioners whose work is related to helping others. They are not active in their work and indifferent to others due to long-term engagement in this type of work. As well as the phenomenon of negative attitudes towards work, Maslach et al. believe that "Job burnout is a state of physical, mental, emotional and behavioral exhaustion caused by too long working hours, too much workload, too high work intensity and ignoring one's individual needs in the process of work". Maslach believes that job burnout should include three dimensions: emotional exhaustion, cynicism, 
and low sense of accomplishment.

The job burnout of primary and middle school teachers is mainly manifested as: decreased work enthusiasm, laziness in student affairs and teaching work, inability to feel professional achievement and happiness, etc., physical fatigue due to fatigue, psychological anxiety, irritability, behavior Be lazy. Teacher burnout has become a prominent problem in the field of education in our country. It not only consumes teachers' enthusiasm for work, reduces their innovative spirit, reduces their work performance, but also hinders the development of teachers as a whole [2].

\section{CAUSES OF OCCUPATIONAL BURNOUT OF TEACHERS IN PRIMARY AND MIDDLE SCHOOLS}

\subsection{High Social Expectations and Excessive Psychological Pressure}

With the development of society, families are paying more and more attention to the growth of their children, and the requirements and expectations of teachers are also higher and higher. It seems that teachers are omnipotent. Teachers have too many sacred auras, too many social responsibilities, and great mental pressure. Especially under the current entrance examination system, in order to achieve good results, teachers have to work long hours, heavy tasks, high demands, and high pressure. Once a child's grades are not satisfactory or something goes wrong, it will be blamed on the teacher, and some parents will ask the teacher from time to time. Under the inertial thinking that "examination scores determine everything", teachers carry a heavy mental burden. If this continues, it will aggravate teachers' job burnout.

\subsection{Biased Public Opinion Orientation, Low Social Identity}

Some social media’s "funny hunting" psychology often pays attention to the negative news of individual teachers, and from this they generalize and misunderstand the entire group of teachers. The hard work of teachers cannot be understood by the society, recognized by parents and the society and due professional respect, let alone professional happiness and pride. If things go on like this, teachers themselves lack self-confidence in their careers. They are more of inferiority and helplessness, and their career expectations are greatly reduced.

\subsection{Insufficient State Investment and Low Teacher Income}

There is no doubt to say that in recent years, with the rapid improvement of the national economy, the country has also increased the salary of teachers. However, as a job with high standards and strict requirements that bears huge social pressure, compared with many industries, the hard work and income of teachers are not equal. The society has too high expectations of teachers, and the hard work of teachers and teachers' actual economic benefits form a strong contrast. If this psychological gap cannot be effectively alleviated, it is also an important cause of teacher burnout.

\section{THE INFLUENCING FACTORS OF TEACHERS' JOB BURNOUT IN PRIMARY AND MIDDLE SCHOOLS}

\subsection{The Influence of Gender on the Job Burnout of Teachers}

Most research results show that gender has a certain influence on the degree of depersonalization of primary and middle school teachers, and the degree of depersonalization of male teachers is significantly higher than that of female teachers. According to the matchmismatch model proposed by Leiter and Maslach, job burnout is closely related to the match of the individual with the job. Compared with female teachers, the gender role of male teachers carries more social expectations such as personal success and achievement. This is in contrast to the borderlessness and long-term effectiveness of teachers' work. More serious role conflicts than female teachers, role conflicts aggravate male teachers' job burnout.

\subsection{The Effect of Teaching Age on Teachers' Job Burnout}

Teachers of different teaching ages have differences in multiple dimensions of job burnout, especially in teachers with a teaching age of 11 to 20 years, the degree of emotional exhaustion and depersonalization is significantly higher than that of teachers with a teaching age of less than 5 years. The dual responsibility of "taking the lead" in the school and "filial piety and teaching at home" makes teachers around middle age and later face the challenge of "middle-age crisis".

\subsection{The Influence of Social Support on Teachers' Job Burnout}

Research results at home and abroad have shown that social support and its various factors have a good negative predictive power on the job burnout of primary and middle school teachers [3]. The subjective support and the utilization rate of support in social support have a greater impact on job burnout than objective support, indicating that in the process of preventing job burnout of primary and secondary school teachers, not only objective support must be provided, including care and respect from family members and society [4]. 


\subsection{The Influence of Psychological Capital on Teachers' Job Burnout}

All dimensions of psychological capital and job burnout are above medium level, and there is a significant negative correlation. Psychological capital can effectively alleviate job burnout, especially dehumanization and low sense of achievement [6]. As a kind of superior resource, work resources can supplement teachers' psychological energy, make teachers actively cope with work pressure, maintain good physical and mental state, and regulate the negative emotions brought by high-intensity work pressure. As an individual's work resource, psychological capital enables individuals to have the confidence to face challenges, make positive attribution to the results, and quickly adapt to and surpass the negative experience and changes of the external environment, so as to reduce the job burnout of teachers.

\section{THE DEFECTS AND PROSPECTS OF THE RESEARCH ON TEACHERS' JOB BURNOUT}

The study of primary and secondary school teachers' job burnout has achieved preliminary results. The current situation of teachers' job burnout has been gradually clarified from point to aspect, and the main influencing factors of teacher job burnout have been basically clarified. However, there are still some unsolved problems in the study of primary and secondary school teacher job burnout in terms of theoretical guidance, content focus, and method types.

The research on job burnout of primary and middle school teachers still lacks theoretical guidance and support. In domestic empirical research on the attribution of teacher burnout, almost all researchers collect data through research methods such as interviews or questionnaire surveys, and then conduct data processing and analysis. Domestic researchers have not yet explained the underlying reasons behind the phenomenon of job burnout of primary and middle school teachers from the height of theoretical construction. Theoretical construction should become the main direction of speculative research on job burnout of primary and middle school teachers in the future.

Existing studies on job burnout of primary and secondary school teachers are all cross-sectional studies. This type of research can reveal the job burnout status of primary and secondary school teachers at a certain point in time or within a short period of time, and belongs to the category of static research. However, "job burnout is a continuous and negative mental state related to work experienced by individuals”. The formation of teacher job burnout is a continuous process with dynamic changes, which may last a long time. The inside is not perceived by the individual. Therefore, researchers should pay more attention to the follow-up longitudinal research on the job burnout of primary and middle school teachers.

\section{CONCLUSION}

In the context of rapid development of science and technology and education reform, the pressure faced by teachers is gradually increasing, and the phenomenon of teacher burnout has aroused more and more attention. There are many reasons for job burnout, including society's expectations of teachers, parents' emphasis on education, the pressure of public opinion that teachers face, and national policies. There are also many factors that affect teacher burnout. Teachers' professional expectations, social support, psychological capital, teaching efficacy and teaching age will all have an impact on job burnout. Therefore, it is very necessary to conduct research on teachers' job burnout and reduce teachers' job burnout.

\section{REFERENCES}

[1] WangMengyi, Zhang Shuangshuang. From Western Concepts to Local Studies: A Review of Chinese Social Workers' Job Burnout Research [J].Journal of Aba Normal University, 2018,35(04):102-108.

[2] Sun Tong. On the Causes and Countermeasures of Job Burnout of Primary and Secondary School Teachers [J].Out-of-School Education in China, 2018(23):41-43.

[3] Shao Laicheng, Gao Fengqin. Research on the Current Situation of Job Burnout of Primary and Secondary School Teachers and Its Relationship with Social Support [J].Journal of Shandong Normal University (Humanities and Social Sciences Edition), 2005(04):150-153.

[4] Wang Dajun. Current Situation and Cause Analysis of Job Burnout of Primary and Secondary School Teachers in Henan Province [J].Journal of Zhengzhou University (Medical Science), 2015,50(01):110-114.

[5] Xu Fuming. Current Situation of Job Stress of Primary and Secondary School Teachers and Its Relationship with Job Burnout [J].Chinese Journal of Clinical Psychology, 2003(03):195-197.

[6] Zhang Lili. Review of Researches on Librarian Burnout in Recent 20 Years -- From the Perspective of Psychological Capital [J].Journal of Weifang University, 2020,20(02):93-96.

[7] Zhang Jianren, Yang Ziguang, Ling Hui. The Relationship between Job Stress, Job Satisfaction and Job Burnout of Primary and Secondary School Teachers [J].Chinese Journal of Clinical Psychology, 2014,22(05):920-922. 
[8] A meta-analysis of the influencing factors of job burnout of primary and secondary school teachers [J].

[9] Duan Junli. Analysis of Career Development Planning and Job Burnout Influencing Factors of Primary and Secondary School Teachers [J].Journal of Jilin Institute of Education, 2019,35(09):66-69.

[10] Liao Chuanjing, He Chengcheng, Du Qizhi, et al. A Comparative Study on Professional Mission and Job Burnout of Primary and Secondary School Teachers [J].Journal of Ningbo University (Education Science Edition), 2019,41(06):115-122.

[11] Liao Chuanjing, He Chengcheng, Du Qizhi, et al.A comparative study of vocational mission and job burnout of primary and secondary school teachers [J].Journal of Ningbo University (Education Science Edition), 2019,41(06):115-122. 